\title{
Social contact and encounter in asylum seeker reception: the Utrecht Refugee Launchpad
}

\author{
Caroline Oliver $^{1 *}$ (D), Karin Geuijen ${ }^{2}$ and Rianne Dekker ${ }^{2}$
}

\author{
* Correspondence: c.oliver@ucl.ac.uk \\ ${ }^{1}$ Institute of Education, University \\ College London, 20 Bedford Way, \\ Bloomsbury, London WC1H OAL, UK \\ Full list of author information is \\ available at the end of the article
}

\begin{abstract}
The Utrecht Refugee Launchpad was an experiment at city-level to create a more inclusive form of asylum seeker reception. The initiative used co-housing, bringing together young, local tenants with asylum seekers to improve social integration and local relations. This article examines the nature of social contact, and considers the value of relationships developed between asylum seekers and tenants, using qualitative data from interviews and participant observation. Our findings demonstrate the importance of context, as we show that the remote logics of the national asylum system imposed spatial and temporal limitations on the co-housing model to generate 'adjacent' and transient living. However, at times -through both accident and designcontact was developed with more ease: when there was an equal ratio, similarities between populations, low numbers (of around 80 people in total), access to shared space, and high commitment to the project's 'disposition to friendliness'. While we conclude that relationships proved ephemeral rather than sustained, the initiative nevertheless held promise by enabling asylum seekers brief escapes from landscapes of indifference encountered during reception. Recognising how wider institutional contexts impact on the development of contact however helps innovations like these to achieve a greater potential for transforming relationships and values in urban space.

Keywords: Asylum seeker reception, Encounter, Co-housing, Local turn, Refugees, Social contact
\end{abstract}

\section{Introduction}

Sassen (2012, p. 1) conceives of the city as a 'frontier zone' where different actors meet, and which holds the potential to reposition the immigrant and the citizen as urban subjects, rather than essentially different subjects' (Sassen 2012, p. 3). In this article, we consider 'the Utrecht Refugee Launchpad' [U-RLP] as an innovative space of asylum seeker reception that sought to capitalise on the transformative potential of encounters in urban public space (Amin 2012). The initiative, known colloquially as Plan Einstein, aimed to do so by using co-housing, where young tenants were recruited to live on the 
same site as asylum seekers. ${ }^{1}$ It also provided opportunities for asylum seekers and neighbourhood residents to acquire new skills through co-learning English and entrepreneurship. The article explores the nature of contact that developed through cohousing of tenants and asylum seekers, considering how it is created within the parameters of asylum seeker reception. It asks how do institutional contexts influence social contact between asylum seekers and locals? It also aims to consider the effects of these relationships, asking what is the value of connections created?

These questions are important, since securing peaceful coexistence in reception spaces of European cities is an increasingly urgent challenge facing urban policymakers, when asylum seekers and refugees are often constructed by politics and the media as an 'enemy within' (Gilroy 2019, p. 2). In the contexts of humanitarian crisis and increasing applications for asylum, the establishment of new reception facilities in cities can risk provoking feelings of hostility, racialized opposition to incomers and ethnic competition at a local level (Zorlu 2017; Hubbard 2005). Asylum seeker centres may also be felt as places that are 'off-limits' for neighbourhood residents living nearby (see Zill et al. 2020). However, this need not be so, as other research shows how inclusive responses can develop, founded on place-based local identities of hospitality and welcome (Driel and Verkuyten 2019). And while initial hostility might be directed at reception facilities like Plan Einstein, research suggests that these can be short-lived, as hostility recedes as asylum seekers become part of local relations (Bygnes 2019; Whyte et al. 2018). A key means of easing tension locally is by fostering social contact, where habitual routine interactions across difference can play an important role in generating peaceful coexistence (Wise and Velayutham 2009).

In seeking to ease tension locally, is not surprising therefore that governments have become attracted by the promise of relational initiatives, where 'intense engagement' across difference can be seen 'as a recipe for social cohesion' (Ghorashi 2018, p. 657). Research shows that contact initiatives hold promise; Askins' (2016) study of a befriending scheme between local people and asylum seekers in England enabled participants to build an emotional citizenry, aside from exclusionary legal definitions of citizenship (see also Smets and ten Kate 2008). However, initiatives like Plan Einstein can also hold risks and vulnerabilities, and scholars like Wilson (2017, p. 614) demand that their 'different contexts [ ...] are closely scrutinised'. This is because, by nature, encounters across difference are usually unplanned, unpredictable and spontaneous, occurring by chance and by choice in public space. When orchestrated, even to a small degree, their dynamics may be altered. Research shows for example, how contact between newcomers and asylum seekers that is framed within cities' notions of welcome and sanctuary, can lead to unequal 'host-guest' dynamics (Darling 2015; Rast and Ghorashi 2018). Where authority is claimed by the receiver, the consequences can be that asylum seekers are framed as politically passive and marginalised (Darling 2011).

This article offers an original study of a relational initiative in asylum seeker reception, where encounter was a goal and some inhibitors to contact were lifted. It adds to the debates above however, first by responding to Wilson's (2017) urge to make contexts explicit, drawing attention particularly to how social connections were affected by

${ }^{1}$ Asylum seekers apply for protection with a state for reasons of persecution, war or violence when their state of origin is not able or willing to protect them; Refugees are those who have their claim accepted, and who receive a permit to (temporarily) stay. In Dutch policy jargon, refugees are labelled 'permit-holders'. 
'wider structures and discourses [which] filter through to the realm of everyday practice, exchange and meaning making, and vice versa' (Wise and Velayutham 2009, p. 3). In this case, we demonstrate how tensions in the multi-level governance of asylum became significant for outcomes on the ground, as the local initiative's goals for inclusivity were affected by the more remote logics of national asylum-seeker management, oriented more to efficiency, security and containment. The contradictory motives of national and local government in asylum seeker reception meant the initiative was inhibited at times in achieving the conditions identified by scholars as ideal for contact to flourish. Noble (2009) argues that generating intercultural connections is always 'hard work' but we show how it is made easier -or harder- to achieve as a result of the contexts in which connections are formed. Second, we reflect on the nature and character of relationships developed, by considering the role they played in people's lives. This is important, since there remain questions about the value of relationships generated by often quite fleeting, and superficial contact made through everyday encounters (Valentine 2008). As such, we need to consider to what extent these relationships offer an alternative to normalised practices (Ghorashi 2018).

The article begins with an exploration of how social contact is used in policy paradigms, particularly through co-housing initiatives. We then consider research on contact, encounters, urban connections and friendship, relating these to Plan Einstein, before outlining the methodology and findings. The conclusion reflects upon how contact was affected, how initiatives like this could have a higher likelihood of fostering contact in a sustainable way and ultimately, we reflect on the value of relationships developed in such initiatives.

\section{Social contact: policy perspectives}

Facing outwards onto a block of flats outside a large converted office building, a banner exclaimed 'Socius ${ }^{2}$ young people and refugees live here together' (Fig. 1). It summarised one of the pillars of Plan Einstein, an innovation developed by a horizontal multi-sector alliance in Utrecht to create meaningful alternatives to existing asylum seeker reception. The partnership brought together Utrecht's local government, a housing corporation; a non-governmental organization and further and higher education organizations (Oliver et al. 2019). It exemplifies well 'the local turn' in migration policy-making, where cities develop their own priorities on migration, at times at odds with national policies (Caponio and Borkert 2010; Scholten 2013). Vertical multi-level governance helped, as funding for the project came directly to the city under the European Commission's Urban Innovative Actions scheme.

Plan Einstein opened in November 2016 in Overvecht, a deprived district of mixed high-rise and low-density post-war housing at the Northern outskirts of Utrecht. Utrecht is an ancient university town in the centre of the Netherlands. It is the fourth largest city in the Netherlands, with around 350,000 residents, ${ }^{3}$ with a young, growing demographic and active cultural life. Pressure on housing is intense, so it was significant that the initiative provided apartments for locals to rent. It also offered neighbourhood residents free access to educational opportunities alongside asylum seekers. According to a deputy

\footnotetext{
2'Socius' is a housing company, with a track record in creating and facilitating community living.

${ }^{3}$ See: https://www.utrecht.nl/this-is-utrecht/
} 


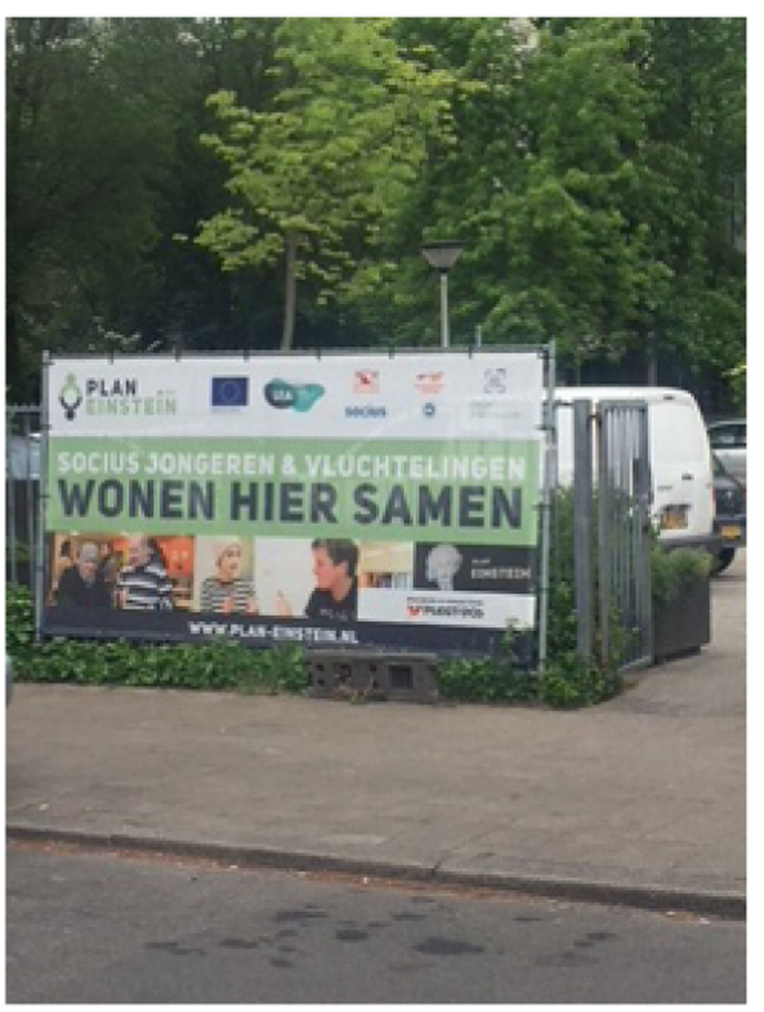

Fig. 1 Socius youth and refugees live here together'. Photo by authors

mayor in the city, the project was conceived during the European refugee 'crisis' of 201516 , 'as an answer to the protests and complaints' arising from plans to locate a new asylum seeker centre (ASC) in the neighbourhood. Protests against ASCs were occurring in other Dutch localities, reflecting increasing negativity in public and political debate on migration, and support for nationalist, anti-immigration parties in the Netherlands. As such, contact between asylum seekers and locals became a key objective of Plan Einstein, not only to contribute to asylum seekers' activation and wellbeing, but to ease local tensions too.

In using co-housing, Plan Einstein pursued a new agenda in policy approaches on asylum seeker reception. This is in the wake of, as Kreichauf (2018) observes, a trend towards 'campization' in European cities arising from policy and law changes in the aftermath of large-scale refugee arrivals in 2015-16. This term refers to a process of increasing concentration of asylum seekers into camp-like structures, with a closed character, and at the cheapest costs. It is an apt description for conditions in the Netherlands, where asylum seekers are isolated in provision designed to be 'basic but humane' (ACVZ 2013). Asylum seekers are housed in large numbers, often in converted facilities like disused army barracks, for reasons of cost efficiency and security. ${ }^{4}$ Isolation is compounded by their regular and sudden movement between centres, a prohibition against working more than 24 weeks a year, and delayed provision around integration and settlement (such as Dutch language classes) which is provided only once people are granted a permit to stay. ${ }^{5}$

$\overline{{ }^{4} \text { See: https://www.coa.nl/en/reception-centres-0 }}$ 
Plan Einstein's organisers were able to capitalise on pre-existing policy ideas on cohousing which has gained traction in the Netherlands in recent years. Co-housing refers to grouped housing of individual household units and shared spaces, where residents are committed to participate in the facility's design and management (Tummers 2016). Projects are driven by the social inclusion of disadvantaged groups, such as older people or persons with autism; they correspond with societal trends of decentralization, custom-made solutions and a demand for increased participation and self-reliability (ibid.). Recently, the model has been extended towards refugees in the Netherlands, including in three locations in Amsterdam (Czischke and Huisman 2018). To date there is only limited systematic evidence on the effects of co-housing on resident satisfaction, social cohesion and migrant integration (Tummers 2016) although some research documents promising signs of social connections forming across ethnic boundaries (Czischke and Huisman 2018). In the Amsterdam case studies, certain conditions helped: shared demographic characteristics, local conditions and access to employment and education opportunities (ibid.). Using co-housing for asylum seekers (individuals without, as yet, a staying permit) was, however, unprecedented.

\section{Social contact: research perspectives}

Plan Einstein could draw on a wealth of academic research that demonstrates the benefits of social contact for enhancing intercultural understanding (Allport 1954; Hewstone et al. 2018). However, bringing people together is not in itself sufficient to produce better relations, and various conditions are needed for spatial proximity to translate into social proximity. The social psychologist Allport (1954) identified four essential conditions: 1) equal status between groups, 2) reliance on each other to achieve a shared desired goal, 3) intergroup cooperation (where members work together in a non-competitive environment) and 4) a supportive institutional context, generated through authorities, law or custom. Pettigrew (1998:7) adds a fifth condition of 'friendship potential', referring to a temporal aspect, where friendship comes from repeated contact and has 'time ... to develop' (see also Neal et al. 2016).

Literature within sociology, geography and anthropology confirms how contact can generate intercultural acceptance (Amin 2002; Neal et al. 2016; Wessendorf 2014). Encounters with difference through everyday, habitual contact produces 'local liveability' (Amin 2002, p. 959) especially within 'micro-publics': sites such as libraries and allotments, that provide vital spaces for momentary acts of conviviality (ibid.). However, Wilson (2017) suggests that when 'managed' (as in the case of Plan Einstein), encounters need careful scrutiny. Questions are raised too over the value of relationships generated by often quite fleeting, and superficial contact made through everyday encounters (Valentine 2008).

In considering the value and depth of connections further, research on 'friendship' in urban contexts offers useful insights for Plan Einstein. This scholarship departs from normative assumptions of friendship as 'egalitarian' and 'uncorrupted', instead demonstrating empirically how, as a specific form of affinity and relatedness, friendship actually is, in 'thrown together' urban settings (Ghorashi 2018; Kathiravelu and Bunnell 2018). Friendship is culturally specific, but can be defined as referring to interpersonal

${ }^{5}$ See: https://www.rijksoverheid.nl/onderwerpen/asielbeleid/vraag-en-antwoord/mogen-asielzoekers-werken 
relationships, which are voluntarily entered into, and based on qualities like trust, reciprocity, fluidity, openness and informality (Amrith 2018). In contexts of migration and urban life, research shows however friendships to be complex, ambivalent and ephemeral (Werbner 2018). Far from the ideal, friendships may be adopted for reasons of convenience, characterised by suspicion and limited trust, and subject to a lack of durability, as friendships fail to endure the changes of status, life-course transitions and further mobility (Kathiravelu and Bunnell 2018).

We put this scholarship to work in the article by first, analysing how far the conditions for contact identified by Allport and Pettigrew were present, and facilitated or hindered by the institutional set-up. Second, we reflect on the nature and value of relationships that emerged, with reference to research on encounters and urban friendships.

\section{Methodology}

Empirical material is drawn from a theory-based evaluation of U-RLP, a pilot project with a learning orientation, conducted from early 2017 to late 2019 (Oliver et al. 2019). The research team worked as part of the partnership delivering the project, but we had a defined and independent role within it. This article uses qualitative data generated with tenants, asylum seekers and partners and stakeholders, drawn from the broader mixed methods study. Data on co-learning, another important aspect of Plan Einstein, will be considered elsewhere for reasons of space, although brief reflections on this strand are offered where relevant (and see ibid.)

Data generation occurred during two waves of research in 2017-2018 and 2019 with multiple groups. We interviewed 14 tenants in their late teens or twenties, eight female and six male, with five repeat interviews (19 in total). Tenants were students or young professionals; nine were from Dutch ethnic backgrounds, and the remaining five were from countries in Europe, West Africa and the Middle East. Eighty-three interviews were held with 62 ASC residents (with 21 repeat interviews). These included 42 males and 20 females, with participants from countries including: Syria (33) Yemen (6) Iran (6) Eritrea (5) Pakistan (3) Ethiopia (2) Afghanistan (2) Singapore (1) Burundi (1) Iraq (1) Turkey (1) and Turkmenistan (1). Participants varied in ages between 18 and 57 years old. They came from a variety of family units from single, to individuals seeking family reunion, to a family of seven. Interviews were also held with 21 stakeholders and employees of the partnership organizations, but we use those data sparingly to prioritize participants' voices. Finally, we conducted participant observation of meetings and activities in and around the centre from June 2017 until its closure in October 2018.

Interviewees were selected through convenience and snowball sampling, because obtaining sampling frames was difficult due to data privacy concerns (see methodological appendix, ibid.). This strategy brought risks of presenting only the views of people already most involved, and we aimed therefore also to interview people at the project's peripheries. Even so, the account remains somewhat partial. Semi-structured interview schedules were piloted, and included questions on participants' backgrounds and experiences of living at Plan Einstein. Tenants' interviews were conducted by a Dutch female researcher, Karin Geuijen, and two Dutch Masters students, Margot Bandringa and Tessa Mauw, under supervision. Many interviews with asylum seekers and refugees were conducted first by two female researchers, Karin Geuijen and 
Caroline Oliver, in English or Dutch, using professional translation by telephone in Arabic, Tygrinya, Kurmanji, Oromo, and Farsi where preferred. Twenty-five interviews were also conducted in Arabic, six by a student assistant and 19 by a Syrian Master's student, Raneem Salama, under supervision. The inclusion of younger researchers in the team enabled frank conversations on the initiative.

Interviews took between $45 \mathrm{~min}$ and $3 \mathrm{~h}$. In wave 1, interviews were mainly conducted at Plan Einstein and in wave 2, at a location selected by respondents including respondents' homes, or a public location, like a café or library. Interviews were recorded and transcribed, apart from a few occasions where the interviewee preferred not to be recorded, where the researcher took detailed notes instead (including quotations). The project received ethics approval at both the University of Roehampton and University College London and we took care to ensure participants understood their involvement in the research. We provided flyers in Dutch, English and Arabic and sought informed consent for all participation. Names given here are pseudonyms. Transcribed interviews were analysed in NVivo, initially by considering data to answer evaluation questions (Oliver et al. 2019) then by focusing specifically on factors stimulating and preventing contact, informed by the literature.

\section{The project set-up}

Our findings consider first how far Plan Einstein's institutional set-up met key conditions for contact. In this section, we demonstrate particularly how Pettigrew's (1998) notion of 'friendship potential' (referring to opportunities to develop relationships through repeated and extended contact) and Allport's (1954) recommendation for equality were inhibited by tensions in the design. However, we note that there was a strong commitment to a shared goal and high potential for intergroup cooperation.

From the outset, although Plan Einstein was based on the local partnership's ideal of inclusive 'co-housing', it was inhibited by institutional contexts that dictated spatial separation of the two populations. This was because asylum seeker accommodation is managed by the Central Agency for the Reception of Newcomers (COA) an executive agency of the Dutch Ministry of Justice. As a result, asylum seekers lived in a COAmanaged ASC on one side of the building (See Fig. 2, to the right of the line) and tenants in a separate part of the building (on the left), managed by Socius, a housing company and partner in Plan Einstein. The two zones were demarcated territorially, by means of a hedge running between the Socius outdoor space and the COA side. Access to the ASC was also via a separate car park barrier. Boundaries between the accommodation were maintained on the ASC side by COA guards, for security reasons, who stopped anyone other than ASC residents from entering, unless by special invitation. Tenants' studios were also only accessible to tenants and the building managers, with their hallways locked to others. One of the tenants, Hasan reflected that the set-up was 'logical, but it is still a kind of separation'. It did not lend itself easily to building relationships, especially inhibiting 'friendship potential'.

The territorial division reflected inequalities between the populations too. The ASC was designed to house 400 asylum seekers in about 100 rooms, whereas there were only 38 studios on the Socius side. In the ASC, residents shared rooms, with four single persons or a family of four or five to a room. Echoing Kreichauf (2018), the ASC was referred to as a 'camp', indicating something of its basic and closed character. Habib in 


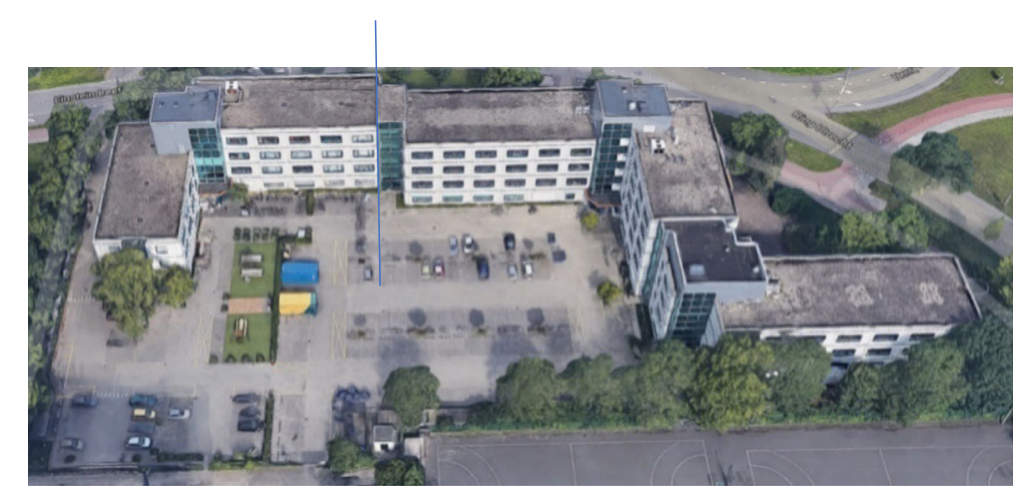

Fig. 2 Plan Einstein in Overvecht (from Google Earth (https:/tinyurl.com/y7mxpfah))

his 30s from Yemen explained, 'You have beds and that's it'. Inhabitants could use a kitchen during certain hours, but they had no private, individual space, and were unable to personalize their living quarters. Across the complex, by contrast, Socius tenants rented private rooms, sharing a kitchen and a common 'living room' area with others on the same floor. As a condition of subsidised rent, they decorated their rooms and common space, creating a private space that tenants referred to as 'home'.

These material inequalities between the groups did not go unremarked upon. Kadin, a Syrian in his late teens noted, 'I live in a room with [four people]. In a room of the same size at the other side lives one person'. Others, like Faisal, a Syrian in his twenties rationalised the inequalities with reference to tenants' legal and financial situation. He explained, 'I know the youngsters live one person in such a room. That is ok since they pay money'. While he understood the reasons, he reflected however that, 'not all people know'. Certainly, the inequalities created awkwardness for tenants and some sought strategies to alleviate it. For example, two tenants outlined their tacit agreement that they would not invite ASC residents to their rooms. Stefan explained:

We agreed that we actually do not have refugees, in our part of the building. They are allowed to enter the communal area of course, but not up the stairs ... simply because we do not want to get any long faces 'why one is [like this] and another isn't ... ?' Yes, we live in the same building, but it looks very different. We really have a lot more space than they have per person.

This strategy, engineered to avoid awkward confrontations with inequality, nevertheless made tenants complicit with the territorial separation and limited the friendship potential within the initiative. Symbolically, it signalled a limited depth of relationships imagined, since friendship usually flourishes across both private and public space (Kathiravelu and Bunnell 2018). 'Equality' was compromised and 'friendship potential' (Pettigrew 1998) jeopardised by the institutional framing of asylum seekers as a population set apart.

The constraints to contact embedded in the housing arrangements continued through temporal boundaries set around the project. The project received European funding for 3 years, but the deputy mayor also promised the neighbourhood at the 
height of the initial protests that the ASC would be closed after 2 years. This seems a reasonable duration for relationships to grow, but in reality, the time was limited much more than this, as a result of unexpected delays to the arrival of asylum seekers (explained in the next section) as well as transience. The efficiency logics of COA meant ASC residents were moved regularly to other centres with only 2 weeks' notice. This meant that in little over a year, 904 asylum seekers moved through the ASC, with the average length of stay being just over 4 months. This included those moving out to their own accommodation after being granted asylum. However, despite the local government's 'continuous line' (doorgande lijn) policy of aiming to keep those refugees within Utrecht, $65 \%$ of Plan Einstein's permit-holders were placed away from the city. ${ }^{6}$ Tenants by contrast, protected by housing contracts of up to 2 years, lived at Plan Einstein with more stability: between November 2016 and October 2018, 53 people moved through the 38 units, with the average rental period being around 18 months. These institutional arrangements marked both inequalities in living conditions, but also indicated major disruption to friendship potential.

Finally, inequalities between populations occurring through legal status affected relations. Tenants were citizens, who attended education or work in their daily lives, while asylum seekers' legal status kept them inactive while they waited for a decision (Ghorashi et al. 2018). Claude, from Burundi explained with reference to ASC residents that, 'most people only go outside the camp to go to the supermarket. They have nowhere to go.' This had implications as some asylum seekers reflected how they had higher expectations for contact with the busy tenants. Hasan, a tenant, reflected too that this situation created some awkwardness for even habitual greetings used in casual encounters:

Some questions like, 'what do you do in everyday life?'... These [asylum seekers] don't actually do anything. They have to figure out themselves what they should do. There are a few activities here, but generally [... ] So when I ask that question to them you often see a bit of a kind of shame, like, 'yes we actually have nothing to do, we're sitting here all day long.

Table 1 summarizes how Allport's condition of equal status and Pettigrew's (1998) of friendship potential were therefore affected already in the project set-up:

Despite these constraining factors emerging through conditions of seeking asylum, different dynamics for 'friendship potential' were promoted by the partnership locally. Integral to the project design was an 'incubator' on the ground floor of the Socius building, comprising a kitchen, lounge area, tables and chairs and two classrooms for common use. Outside, there was a garden area with picnic tables and barbecue. The space was anticipated to become a common social resource that might bind inhabitants together (see Neal et al. 2016). For asylum seekers, it took on special significance as a 'different' and more 'homely' space away from the ASC. Saeed from Yemen experienced the incubator as 'energetic' and 'friendly'; a place where he could study or read in ways impossible in the ASC. It gave ASC residents access to a more normalised and alternative existence. Some even referred to it as 'a living room', while Leilani, a woman in her

${ }^{6}$ Data request to COA. 
Table 1 Accommodation and conditions at Plan Einstein

\begin{tabular}{|c|c|}
\hline Asylum seekers & Socius tenants \\
\hline $\begin{array}{l}\text { Allocated housing in 'camp' provided by the } \\
\text { state, } 4 \text { people in } 1 \text { room, no ownership }\end{array}$ & $\begin{array}{l}\text { Elective rental of housing at subsidized rent, } 1 \text { person in } 1 \\
\text { room, co-ownership through 'home-making' }\end{array}$ \\
\hline $\begin{array}{l}\text { Subject to decision to be moved with } 2 \text { weeks' } \\
\text { notice }\end{array}$ & Housing contract for up to 2 years \\
\hline $\begin{array}{l}\text { Fundamental legal insecurity, limited right to } \\
\text { work or study }\end{array}$ & Citizenship, full rights \\
\hline Daily life characterised by waiting & Working or studying \\
\hline
\end{tabular}

twenties from Iran described how she used to look down into this space from her window in the ASC and imagine another life.

Finally, Allport's (1954) second and third conditions of intergroup cooperation and reliance on each other for a shared goal were present in Plan Einstein's set-up. This was generated through the project's 'disposition towards friendliness', or as many tenants referred to, a sense of 'cosiness' (gezelligheid) associated with it. Institutional support was provided by Socius, the housing company, who recruited diverse tenants for their pro-social attitudes and commitment to the project's ideals (in addition to a low rent and lack of suitable housing elsewhere in Utrecht). Peter, a tenant explained, 'many youngsters who came to live here [came] with the motivation to do something'. Luc joined from another shared living initiative (with people with autism) and expressed that he 'wanted to live in a house with [ ...] a special goal'. Signing up to the project meant accepting self-managed responsibilities to arrange events to bring people together, and associated tasks like preparing food for people to eat together.

Such responsibilities might arguably undermine the spontaneous and elective nature of friendships, risking instead generating dynamics of 'helping' asylum seekers (Darling 2011, 2015; Rast and Ghorashi 2018). However, Socius was clear that Plan Einstein was no 'volunteering camp'. Contact was aspired to as a nudge more than an obligation. Antoine explained he felt 'kind of' expected to develop contacts in a way that was 'the same as if you're working on your fitness and you have to go to the gym. Not negative'. Neither was the pro-social orientation and disposition to friendliness one-sided, as Hasan, a tenant, explained that when involved in small talk with asylum seekers, ' $I$ [ ...] notice that they are very open to this'. Interviews showed that many of the asylum seekers craved contacts with Dutch people (Rast and Ghorashi 2018). The project's shared disposition to friendliness provided an answer to this desire, and though it did not guarantee contact, it established a promising atmosphere for nascent connections to grow.

In summary, Plan Einstein's set-up reflects a mixed picture in achieving ideal conditions for contact. Equality was compromised and institutional support was ambivalent: present in the ideals of the local partnership, but compromised by the physical arrangements imposed by the national government agency. Many social, symbolic and spatial boundaries remained, which jeopardised the potential for friendship to flourish. Conditions of shared enterprise and intergroup cooperation were high, albeit based on a loose disposition. In the next sections, we outline however that as the arrangement changed, so too did contact.

\section{Phase 1: convivial contact}

Despite constraints in the set-up deriving from the usual practice in the national asylum system (identified above) the start-up from February to August 2017 saw 
relationships between asylum seekers and tenants develop with ease. Allport's second and third conditions (a shared goal and intergroup cooperation) were strong at this stage. Yet, most importantly, Allport's (1954) and Pettigrew's conditions of equality and friendship potential were more easily achieved, as circumstances accidentally allowed more favourable spatial and temporal contexts than facilitated by the design. The ASC was expected to run at full capacity of around 400 people from February 2017, but in reality, COA was only able to place 40 asylum seekers there. This was because first, following the EU-Turkey deal in early 2016, the numbers of asylum seekers dropped; and second, issues with the contractor meant the building was not fully ready to open. The delay caused anxieties for the partnership, since it reduced the project's duration. Yet, ironically, it also enabled a serendipitous fusion of contexts, creating conditions more conducive to contact.

First, and most importantly, Allport's condition of equality was facilitated through smaller numbers and a more balanced ratio of tenants and asylum seekers than anticipated. Peter, a tenant, explained that with only 40 asylum seekers, he knew everyone personally, and this generated a 'fantastic atmosphere'. Tenants and asylum seekers also shared similar demographic characteristics; most of the (mostly male) asylum seekers were young, single, well-educated and had good English language skills. Inequalities of legal status were less significant, since most of the ASC group had also received a residence permit or were likely to receive one, creating more optimism among them. As such, the participants were able to build 'room-mate'-like connections or friendships through perceived commonalities and more equal status.

The delayed opening of the COA building meant territorial separation was reduced too, enhancing the friendship potential. As the project began, both groups used the same Socius point of entry to access their respective accommodations (on the inside corner of the left hand side of the building in Fig. 2). Asylum seekers needed to use the kitchen in the incubator space to prepare their food. This provided vital opportunities for regular, habitual contact and 'hanging out' (see Amin 2002) which were boosted to by the start-up coinciding with the milder and longer days of Spring into Summer. Janneke, a tenant in her 20s explained the project at this time was 'really fun', characterised by spontaneous encounters like water fights and barbecues:

We can think back like oh yeah that first part went really well, so naturally, so organic, so nice, that it simply ... Because you came home and somebody was smoking outside and then you had a conversation about the Quran or so.

Faisal, a Syrian asylum seeker in his twenties recounted:

I was depressed when I lived in all these [other] ASCs. Refugees all come from a bad situation. They talk about Syria all the time. They worry. They have negative energy. Here at Plan Einstein, Dutch students bring positive energy [ ... ] In other camps we do not know each other. In Plan Einstein we were a smaller group, eating together. So we know each other a lot. We sit at the end of the day, also with Iranians and Pakistani. Being a small number helps remember names, stories. We shared a kitchen and shared stuff. 
For the few asylum seekers living there, the delay in the ASC's full opening brought relief from large-scale and depersonalized ASC life. Even the COA staff were perceived as more relaxed, as Omar, a friend of an ASC resident said: 'We knew even the COA security guards, we played games with them ... ' Faisal felt in contrast to other ASCs, It was a good place for refugees to know each other'. Crucially, however, it gave also exposure to difference in the form of the Dutch tenants, which brought relief and lightness, rather than 'negative energy'. Eymen from Turkey explained that in the ASC, 'people talk always about the asylum procedure and not about standard things', whereas with the tenants he felt, 'you can talk with them about different stories and different topics'. This resonates with Killias' (2018) study of Iranians in a Malaysian high-rise, which shows how they opted for relationships with Western students. Those friendships were considered less complicated and more fun than relationships with co-ethnics, which were tinged by fears of betrayal and concerns of political surveillance.

A few asylum seekers reported limited contact, but in those situations, inequalities remained, especially in legal status, but also in age and educational backgrounds. For example, Samir, a man in his forties had left Iraq in 2015 in order to provide a safe passage for his family, but had not received refugee status. He spoke Arabic, limited English and no Dutch, and explained he had 'little contact with the students [ ...]' and found there to be 'few conversations on a daily basis'. Maahir also did not experience much contact, although by contrast, he was a high status Pakistani medical doctor in his forties, who also had his application for asylum refused.

In summary, building relationships in the first phase from February to August 2017 was positively affected by the institutional contexts, somewhat by design, and yet also through accident and delay. These factors reduced inequalities built into the set-up, in ratios and status, and enabled higher friendship potential through chances for habitual contact at entrances, in outdoor space and through easy access to the incubator space. In this way most of Allport's and Pettigrew's conditions for social contact were met.

\section{Phase 2: adjacent and transient living}

Despite this promising start in Spring 2017, we found that by late 2017 few of the tenants actively initiated contact with ASC residents. Relationships had become more lukewarm, akin to amicable, neighbourly relations than the 'room-mate' like relationships seen in the first phase. We explain this shift in contact as a result of the institutional design reverting back to the set-up conditions. This affected the spatial and temporal parameters of contact and meant fewer conditions of contact were met. In this phase, the situation became more akin to adjacent, side-by-side and transient living, rather than face-to-face shared living.

The shift occurred from August 2017, when the ASC was ready and the original plan to place 400 asylum seekers could become a reality. It is important to consider that the initial phase, until then, was purely a makeshift and temporary solution until COA was able to populate the ASC fully, in line with Dutch national policy. The sudden increase in population however had negative consequences for conditions of contact. The vastly different ratio disrupted equality between the groups, especially as the asylum seeker population was dissimilar in composition too. More were middle aged, there were more families with children, and fewer spoke English as a common language. The familiar knowledge of 'the other' was replaced by feelings of anonymity and unfamiliarity, 
disrupting friendship potential too, in what had by then, had become the tenants' 'homes'. Janneke described:

When all of a sudden there lived two or three hundred people and the churn was high, then ... I just stopped engaging. That that simply ... it became too anonymous. I no longer had any idea who was there and what they were doing.

Anne explained the impacts on depth of relationships:

[...] and when you do go and sit next to someone, then you'll have a superficial conversation like 'how are you?' But it hasn't gone much deeper than that, since really so many people came to live here.

Higher numbers invited more caution among tenants, similar to Amrith's (2018) observations of risks for migrants in developing friendships in São Paulo's transient commercial districts. For example, Misha explained the reasons that she locked her door: partly by habit but also as: 'It's not that I don't trust anyone, but it's a big project, everyone can walk in'. The shifts had impacts on friendship potential for asylum seekers too; while most in the first phase had been granted status and moved out to their own accommodation, others remaining like Faisal, felt depressed and alone again as Plan Einstein 'became a regular camp'. He explained:

When they brought the big number of refugees, we didn't see the Dutch students anymore. They changed the entrance of the camp. There were all the women and children. We lost contact with the students. It is hard to make connections now.

Changes in the entrance facilities affected friendship potential by limiting opportunities for habitual contact. Once the ASC building was fully populated, asylum seekers entered their accommodation using a different entrance on the far corner of the complex (see Fig. 2). At the same time, given the concerns for security raised above, the Socius housing manager then locked the main door to the shared incubator space, only allowing access during planned events and activities, like the monthly games night. This was because the main door to the Socius building was no longer monitored by COA security personnel, as they had moved to the other entrance across the complex. In this way, opportunities for regular contact, not only in the incubator space, but also around the entrances and stairwells were diminished, affecting not only contact but the project's atmosphere of 'cosy friendliness', as Anne, a tenant explained:

When the complex was finished there came a new entrance, then you saw each other less because you no longer walked along together. And the door was always locked again. So you notice that it's a lot less cosy now.

As such, the changes in the physical spaces had ramifications for commitment to the shared endeavour - another condition for social contact, according to Allport (1954). The high spirits and cooperative endeavour of 'getting things going' was already weakened by the extended wait for the project to start; Janneke, a tenant, explained 'the 
motivation is then gone'. The arrival of significantly more ASC residents coincided too with late summer when students like Anne, were 'not often at home'. She explained how, 'now with school I'm also quite busy. I do try to find time for it Igetting to know the asylum seekers] but I find it increasingly more difficult'. The shared vision of friendliness and 'nudged' informal contact increasingly became replaced by tenants' concern that this was one-sided voluntary labour. With the higher numbers, it was intensive labour at that, which chafed with tenants' other commitments. Misha explained, 'we try to organize the food together again [but] it's difficult to make food for so many people'. A small core group of tenants (especially those who were paid for housing management duties) remained committed, but otherwise, 'more and more people dropped off as time went by' (Janneke). In the wake of fewer activities and less easy access to space, some ASC residents shifted their orientations away from the project too. Claude, from Burundi explained that, without the regular activities he went out during the day to study in the library and university (unlike most other ASC residents):

When we came to this place they used to organize barbecues etc. Now they're not doing these activities anymore [... ] I'm not in touch with the Socius students. I met a girl outside, I forgot her name. And one guy through a friend of mine. But most times I leave the place in the morning and only come back in the evening.

At this time, other organised activities like a weekly music meeting, language café and existing classes open to the neighbourhood in English and entrepreneurship offered tenants a 'way in' with families, indicating a different opportunity for intergroup cooperation, one of Allport's conditions for social contact (and a key feature of the colearning activities). However, few tenants attended regularly as they saw no personal benefit in the activities. One exception was Antoine, a tenant who had much closer relations with asylum seekers, speaking Arabic and describing himself as 'one of the few who really does arrange to meet with people'. He helped two Syrian sisters with their Dutch exams and spent Iftar $^{7}$ with their family. Antoine might be described as a 'transversal enabler' (Wise 2009, p. 24), someone who might 'typically go out of their way to create connections between culturally different residents in their local area'. For Antoine, this was through exchanging intercultural knowledge, as he explained:

I have lots of really profound conversations, often about politics. Last night I was at Muhammed's [... ] he has become a good friend, and now has a house where I often visit. I bumped into him outside with that other guy and then he invited me for a cup of coffee. Yesterday I was at his [place] and then we really talked about politics in the Middle East for two hours.

However, Amal, a resident of the ASC described Antoine as an exception,

There are no other students who react to us and that is unfortunate. Maybe it's the same for refugees, not all of them participate, but with the students it is just 1\% out of $100 \%$. I think at least they [could] attend some of the events here and

\footnotetext{
${ }^{7}$ The evening meal at sunset, which marks the end of the daily Ramadan fast.
} 
communicate with some of the people that already come here. Only at the games night, which is 1 day in the month, not even every month, and then we'll just say 'hi' to each other and that's it ...

Antoine realised that he found contact easier than other tenants, and reflected, 'I've got the feeling that I have a more personal touch and they are more formal or something'. Other tenants like Anne felt that it was 'just tricky. There are so many people. Where do you start?' Even Farah, who could speak Farsi because her parents came from Iran, found broaching contact embarrassing and potentially invasive, 'because you don't know exactly how'. She explained, 'I also find it difficult to move up to someone, because even if I do hear that some speak Farsi, then it seems like you're listening. It is difficult.'

In summary, contact was not easy in conditions of adjacent and transient living, and, without any facilitation, it depended on individual motivation and skills. The institutional context hindered the establishment and maintenance of social contacts for many, since it breached and weakened Allport's and Pettigrew's necessary conditions.

\section{Phase 3: waxing and waning contact}

Given the limited contact witnessed by Winter 2017-2018, the partnership invested in creating more optimal conditions to reinvigorate contact. In Spring 2018, they employed two part-time hosts to work in the incubator space during expanded opening hours, where their role, as one of the hosts described was 'to make small talk and give advice'. Shared goals and cooperative working were also reinvigorated by two events. First, the partnership hosted a meeting of Eurocities' Social Affairs Forum, engaging city officials and elected representatives from European cities. Selected tenants, asylum seekers and neighbours were invited to training sessions to learn skills to be able to present the project to delegates. Second, some tenants, asylum seekers and neighbours were united in a challenge to try to bring more people into the incubator space. A theme 'Einstein: Coffee of the world', was chosen whereby the incubator would have the function of a world cafe, where free coffee would be available, and made using different methods from various countries. Participants re-designed the space, painting walls and embellishing the room with plants and Middle-Eastern inspired low seating and carpets. Over several weekends, they were busy 'doing things' together, engaging in practical activities (one of Askins and Pain's (2011) recommendation for creating meaningful encounters).

The activities bonded the (limited number) of tenant and ASC participants through intergroup cooperation, while the café concept shifted the atmosphere of the public space, exemplifying anew the project's shared vision. One of the hosts commented, 'From the moment they redecorated the place, that was an extra stimulant. And it drew more people inside. It looked better, it felt better.' Salman, an asylum seeker from Iran also explained that, 'after they did that [Coffee of the World] we used to hang out a lot ... Especially after, I think people came even more'. Both occasions stimulated intergroup cooperation towards shared goals. They also enabled both groups to contribute significantly on an equal footing, offering opportunities for asylum seekers to contribute rather than only to receive (see Rast and Ghorashi 2018).

On the other hand, these promising attempts simultaneously countered opposing institutional influences, which undermined friendship potential and weakened 
commitment to the goal. The building's closure in Autumn 2018 was looming, and tenants became anxious to secure accommodation in a city where there is high demand for housing. Luc, a tenant explained how commitment waned as, 'the deadline was really coming $[u p$...] Sometimes you think like why should I start up a new thing right now, if this is going to stop in a few months anyway?' This was also the case for ASC residents, when in late Summer 2018, with very little notice and earlier than planned, COA began moving people out of the centre, many away from Utrecht, removing the last remnants of their institutional support for the project. These events lowered friendship potential and reduced the likelihood of contact enduring, with most contact limited to social media connections. Some refugees felt disappointed with the limited duration of their relationships. Nevertheless, a year after the project ended, many participants, both tenants and ASC residents, looked back fondly on the experience. Dalila, a 20-year old Syrian woman, described in Summer 2019 how she felt the tenants, 'helped me a lot to get out of the situation and the idea that I am a refugee, and I live in the refugee camp and my life is miserable'.

\section{Conclusion}

The U-RLP was an innovation in asylum seeker reception that sought a more inclusive approach, to improve social integration and local relations. The first goal of this article was to examine how the institutional contexts affected contact between asylum seekers and locals. It explored how far the arrangement enabled conditions for contact suggested as necessary by Allport (1954) and Pettigrew (1998). These were 1) equality; 2) reliance on each other for a shared goal; 3) cooperation; 4) a supportive institutional context and 5) time for relationships to develop. The findings showed that Plan Einstein facilitated some of these conditions through its co-housing arrangements, particularly conditions 2 and 3. However equal status, a supportive institutional context and friendship potential (1, 4 and 5) were jeopardised, especially through the conflicting objectives at the national and local level around asylum seeker reception.

The findings showed that multi-level governance had tangible effects on contact locally. The local partnership's goal was for inclusivity, enabled through European funding. Yet, its efforts were still highly constrained by operational confines set by the national government's logics: for economic efficiency, security, limited integration and containment for people without legal status. Despite the ideal conditions of the first phase, where contact was light and easy, ultimately the partnership had no power to arrest the imposition of conditions driven by these other logics. As such, it faced a difficult exercise in generating contact in conditions where ultimately over 900 asylum seekers moved through a depersonalised 'camp' in little over a year (see Kreichauf 2018). The ensuing anonymity limited friendship potential, making contact awkward for many, apart from the most committed enablers. Opportunities were inhibited too as asylum seekers and refugees were moved (often far) away from Utrecht as they left the ASC. The territorial set-up of a separate ASC maintained 'adjacent living' rather than living together, demarcating different territories. At times, local actions inhibited friendship potential further, as public space remained closed for much of the time in the middle of the project, and participants refrained from inviting each other into their private spaces. These findings give empirical weight to the importance of recognising how broader contexts affect relational initiatives (see Wilson 2017) showing how 
attempts to generate peaceful coexistence at local level were compromised significantly from the outset.

Yet we also gain rich learnings about how initiatives like Plan Einstein can more likely foster contact in a sustainable manner, even when there are limited opportunities to influence fundamentals. The findings show first how infrastructures really matter, both for friendship potential and as vehicles for communicating a shared goal. Crucially, shared public space must be accessible, open and appealing in ambience. Thought must be given to the role of 'in-between' spaces for casual and incidental interaction; facilities like shared entrances or stairwells give vital opportunities for recognising the same faces and overcoming anonymity. Benefits are gained when both parties are involved in the design of this space, enabling all participants -already subject to stark material and legal inequalities- to contribute on a more equal basis. This ensures it is appealing, while recognising the reasons ASC residents might invest in such spaces, since they are especially valued as offering a more homely environment as an alternative to their experience of depersonalised ASC-life.

Shared living also worked best where there was equality in ratios, and where participants had similar shared demographic characteristics (the latter observation confirming Czischke and Huisman's (2018) findings). Lower numbers also worked better; the higher numbers led to a sense of anonymity that alienated both parties and reduced trust (albeit there is a risk that too small a number increases pressure on a few people). The experiment confirms that practical endeavours help to gel relationships (Askins and Pain 2011) but they must come from a genuine joint interest, with the lack of interest by tenants in activities like the language cafe a testament to this. The broader evaluation shows that co-learning, in which asylum seekers engaged with neighbourhood members in weekly classes, met this condition more easily. Even there, however, contacts rarely endured beyond the project (Oliver et al. 2019).

This brings us to the second question of the article: what is the value of the relationships made within such initiatives? As in Mahieu and van Caudenberg's (2020) study of refugee befriending, this research demonstrates that living under one roof does not guarantee deep or extended social contact. Temporary 'friendliness' was created rather than lasting 'friendship'. Although this suggests that difference was rarely transcended (Kathiravelu and Bunnell 2018) the relations made however need not be considered insignificant (see Vincent et al. 2018). In Plan Einstein, tenants' pro-social motivations created a disposition towards friendliness that met asylum seekers' yearning for contact. Even limited and slight encounters were valued; the friendly nods, and students passing on bicycles gave asylum seekers a window into difference. Glimpses of tenants' regular lifestyles and issues offered them some relief and lightness away from their own and other ASC residents' pressing concerns, and rejection found elsewhere.

To conclude then, we suggest that where Plan Einstein offers most promise, is in the dynamic of contact generated. Tenants' pro-social orientation waxed and waned, chafing with their need to do other things beyond the initiative. Yet the resistance for the initiative become a 'volunteering camp', and inclination -rather than obligation- to make contact, created coexistence based on a dynamic more akin to 'presence' than hospitality (Darling 2015). It contrasted with initiatives where people's desire to 'help', can create more uneasy relationship of host and guest (Rast and Ghorashi 2018). Those dynamics were not absent, yet corresponding with Askins (2016) we conclude that 
initiatives like U-RLP hold possibilities for developing new affinities that would not likely develop without them. How far they reach their potential, however depends significantly on institutional contexts: the constraints of national government's policies on asylum and the extent to which local decision-making and action corresponds with local partners' own goals towards inclusivity.

\author{
Abbreviations \\ ASC: Asylum seeker centre; COA: Centraal Orgaan Opvang Asielzoekers (Central Agency for the Reception of \\ Newcomers); NGO: Non-governmental organization; U-RLP: Utrecht Refugee Launchpad
}

\title{
Acknowledgements
}

The research was funded as part of the U-RLP project, co-financed by the European Regional Development Fund through the Urban Innovative Actions Initiative. We would like to express thanks to the U-RLP partnership for their cooperation with the research. We are grateful too to Margot Bandringa, Tessa Mauw and Raneem Salama, for their contributions to some of the qualitative research and the CentraalOrgaan opvang asielzoekers (COA) for answering queries. Thanks to our research advisory board Ash Amin, Alice Bloch, David Parsons, Peter Scholten, and our research partner Sarah Spencer for inspiration and guidance. We would also like to thank the two reviewers, whose sensitive reading of a first manuscript and detailed comments inspired the development of the manuscript. Finally, we express deep thanks to the residents living in the complex around 'Plan Einstein' for their generous engagement with the research.

\section{Authors' contributions}

All authors contributed to the generation and interpretation of data and read and approved the final manuscript.

\section{Funding}

The U-RLP was co-financed by the European Regional Development Fund through the Urban Innovative Actions Initiative. UIA was not involved in the design of the study or in the collection, analysis, and interpretation of data, nor in the writing of the manuscript.

\section{Availability of data and materials}

The datasets generated and analysed during the current study are not publicly available for reasons of confidentiality but are available from the corresponding author on reasonable request.

\section{Competing interests}

The authors declare that they have no competing interests.

\section{Author details}

${ }^{1}$ Institute of Education, University College London, 20 Bedford Way, Bloomsbury, London WC1H OAL, UK. ${ }^{2}$ School of Governance, University of Utrecht, Utrecht, The Netherlands.

Received: 7 June 2019 Accepted: 3 June 2020

Published online: 27 August 2020

\section{References}

Adviescommissie Vreemdelingenzaken [Advisory Committee on Migration Affairs] (2013). Verloren tijd: Advies over dagbesteding in de opvang voor vreemdelingen [Lost time: Advisory report on activities in reception facilities for foreigners]. Den Haag: ACVZ.

Allport, G. W. (1954). The nature of prejudice. Reading: Addison-Wesley.

Amin, A. (2002). Ethnicity and the multicultural city: Living with diversity. Environment and Planning A, 34, 959-989.

Amin, A. (2012). Land of strangers. Cambridge: Polity.

Amrith, M. (2018). Tentative friendships among low-income migrants in São Paulo's commercial districts. Urban Studies, 55(3), 522-537.

Askins, K. (2016). Emotional citizenry: Everyday geographies of befriending, belonging and intercultural encounter. Transactions of the Institute of British Geographers, 41(4), 515-527.

Askins, K., \& Pain, R. (2011). Contact zones: Participation, materiality, and the messiness of interaction. Environment and Planning D: Society and Space, 29(5), 803-821. ISSN 0263-7758.

Bygnes, S. (2019). A collective sigh of relief: Local reactions to the establishment of new asylum centers in Norway. Acta Sociologica. https://journals.sagepub.com/doi/pdf/10.1177/0001699319833143.

Caponio, T., \& Borkert, M. (Eds.) (2010). The local dimension of migration policymaking (IMISCOE reports). Amsterdam University Press. https://nbn-resolving.org/urn:nbn:de:0168-ssoar-316237.

Czischke, D., \& Huisman, C. J. (2018). Integration through collaborative housing? Dutch starters and refugees forming selfmanaging communities in Amsterdam. Urban Planning, 3(4), 156-165.

Darling, J. (2011). Giving space: Care, generosity and belonging in a UK asylum drop in centre. Geoforum, 42(4), 408-417.

Darling, J. (2015). From hospitality to presence. Peace Review: A Journal of Social Justice, 26, 162-169.

Driel, E., \& Verkuyten, M. (2019). Local identity and the reception of refugees: The example of Riace. Identities. https://doi.org/ 10.1080/1070289X.2019.1611075.

Ghorashi, H. (2018). Commentary: Unsettling friendship and using friendship to unsettle. Urban Studies, 55(3), 655-661.

Ghorashi, H., de Boer, M., \& ten Holder, F. (2018). Unexpected agency on the threshold: Asylum seekers narrating from an asylum seeker centre. Current Sociology, 66(3), 373-391. 
Gilroy, P. (2019). Agonistic belonging: The banality of good, the 'alt-right' and the need for sympathy. Open Cultural Studies, 3(1), 1-14. https://doi.org/10.1515/culture-2019-0001.

Hewstone, M., Al Ramiah, A., Schmid, K., Floe, C., van Zalk, M., Wölfer, R., \& New, R. (2018). Influence of segregation versus mixing: Intergroup contact and attitudes among White British and Asian-British students in high schools in Oldham, England. Theory and Research in Education, 16(2), 179-203.

Hubbard, P. (2005). Accommodating otherness: Anti-asylum centre protest and the maintenance of white privilege. Transactions of the Institute of British Geographers, 30(1), 52-65.

Kathiravelu, L., \& Bunnell, T. (2018). Introduction: Urban friendship networks: Affective negotiations and potentialities of care. Urban Studies, 55(3), 491-504.

Killias, O. (2018). Distant friends and intimate strangers: On the perils of friendship in a Malaysian apartment building. Urban Studies, 55(3), 554-569.

Kreichauf, R. (2018). From forced migration to forced arrival: The campization of refugee accommodation in European cities. Comparative Migration Studies, 6(7). https://doi.org/10.1186/s40878-017-0069-8.

Mahieu, R., \& Van Caudenberg, R. (2020). Young refugees and locals living under the same roof: Intercultural communal living as a catalyst for refugees' integration. Comparative Migration Studies, 8. https://doi.org/10.1186/s40878-019-0168-9.

Neal, S., Vincent, C., \& Iqbal, H. (2016). Extended encounters in primary school worlds: Shared social resource, connective spaces and sustained conviviality in socially and ethnically complex urban geographies. Journal of Intercultural Studies, 37(5), 464-480. https://doi.org/10.1080/07256868.2016.1211626.

Noble, G. (2009). Everyday cosmopolitanism and the labour of intercultural community. In A. Wise, \& S. Velayutham (Eds.), Everyday multiculturalism (pp. 46-65). Hampshire: Palgrave Macmillan.

Oliver, C., Dekker, R., \& Geuijen, K. (2019). The Utrecht Refugee Launchpad final evaluation report. Oxford: COMPAS, University of Oxford. https://www.compas.ox.ac.uk/wp-content/uploads/041219-Final-evaluation-report.docx.pdf.

Pettigrew, T. F. (1998). Intergroup contact theory. Annual Review of Psychology, 49(1), 65-85.

Rast, M. C., \& Ghorashi, H. (2018). Dancing with 'the other': Challenges and opportunities of deepening democracy through participatory spaces for refugees. Social Inclusion, 6(1), 188-198.

Sassen, S. (2012). When the center no longer holds: Cities as frontier zones. Cities, 34, 67-70

Scholten, P. (2013). Agenda dynamics and the multi-level governance of intractable policy controversies: The case of migrant integration policies in the Netherlands. Policy Sciences, 46(3), 217-236.

Smets, P., \& ten Kate, S. (2008). Let's meet! Let's exchange! LETS as an instrument for linking asylum seekers and the host community in the Netherlands. Journal of Refugee Studies, 21(3), 324-346.

Tummers, L. (2016). The re-emergence of self-managed co-housing in Europe: A critical review of co-housing research. Urban Studies, 53(10), 2023-2040.

Valentine, G. (2008). Living with difference: Reflections on geographies of encounter. Progress in Human Geography, 32(3), 323-337.

Vincent, C., Neal, S., \& Iqbal, H. (2018). Friendship and diversity. Class, ethnicity and social relationships in the city. Hampshire: Palgrave Macmillan.

Werbner, P. (2018). Commentary: Urban friendship: Towards an alternative anthropological genealogy. Urban Studies, 55(3), 662-674.

Wessendorf, S. (2014). Commonplace diversity: Social relations in a super-diverse context. Basingstoke: Palgrave Macmillan.

Whyte, Z., Romme Larsen, B., \& Fog Olwig, K. (2018). New neighbours in a time of change: Local pragmatics and the perception of asylum centres in rural Denmark. Journal of Ethnic and Migration Studies, 45(2), 1-17. https://doi.org/10. 1080/1369183X.2018.1482741.

Wilson, H. F. (2017). On the paradox of 'organised' encounter. Journal of Intercultural Studies, 38(6), 606-620.

Wise, A. (2009). Everyday multiculturalism: Transversal crossings and working class cosmopolitans. In A. Wise, \& S. Velayutham (Eds.), Everyday multiculturalism (pp. 21-45). Hampshire: Palgrave Macmillan.

Wise, A., \& Velayutham, S. (2009). Introduction: Multiculturalism and everyday life. In A. Wise, \& S. Velayutham (Eds.), Everyday multiculturalism (pp. 1-20). Hampshire: Palgrave Macmillan.

Zill, M., Spierings, B., \& Van Liempt, I. (2020). The Grandhotel Cosmopolis - a concrete utopia? Reflections on the mediated and lived geographies of asylum accommodation. Comparative Migration Studies, 8. https:/doi.org/10.1186/s40878-020$0171-1$.

Zorlu, A. (2017). Attitudes toward asylum seekers in small local communities. International Migration, 55(6), 14-36.

\section{Publisher's Note}

Springer Nature remains neutral with regard to jurisdictional claims in published maps and institutional affiliations. 